https://doi.org/10.22319/rmcp.v12i1.5999

Nota de investigación

\title{
Características histopatológicas y detección de Papilomavirus en la fibropapilomatosis bovina en el estado de San Luis Potosí, México
}

Isaura Méndez Rodríguez a

Fernando Alberto Muñoz Tenería ${ }^{a}$

Milagros González Hernández a

Alan Ytzeen Martínez Castellanos ${ }^{a}$

Luisa Eugenia del Socorro Hernández Arteaga a*

${ }^{a}$ Universidad Autónoma de San Luís Potosí. Facultad de Agronomía y Veterinaria. Carretera San Luis-Matehuala Km 14.5, Ejido Palma de la Cruz, 78321 Soledad de Graciano Sánchez, SLP, México.

* Autor de correspondencia: socorro.hernandez@uaslp.com

\section{Resumen:}

El objetivo del trabajo fue determinar la presencia del papilomavirus bovino (PVB) en muestras de tejidos de bovinos con lesiones cutáneas sugerentes de papilomas, fibromas y fibropapilomas en unidades de producción de ganado bovino en el estado de San Luis Potosí. Se obtuvieron 11 biopsias de piel de bovinos de entre 5 y 18 meses provenientes de sistemas de producción estabulado, semiestabulado y de agostadero con fines productivos de carne y leche, con lesiones sugerentes de papilomas, fibropapilomas y carcinomas de células escamosas. Estas muestras se procesaron mediante histopatología y se realizó extracción de ADN para la detección del PVB mediante PCR con los oligonucleótidos FAP59/FAP64 y MY09/MY11. Las lesiones se clasificaron en fibromas (45.45\%) y fibropapilomas $(54.54 \%)$ sin que se observara distribución de un tipo de lesión específica de acuerdo a la localización anatómica, edad, sistema de producción o fin zootécnico. El $72.72 \%(\mathrm{n}=8)$ de las muestras mostraron resultados positivos para PVB mediante PCR; $45.45 \%(\mathrm{n}=5)$ con los oligos FAP y $54.54 \%(n=6)$ con los oligos MY. Hasta donde se sabe, este es el primer 
estudio que describe la presencia de PVB en el estado de San Luis Potosí, por lo que estos resultados aportan datos útiles para establecer medidas de detección y control necesarias para mejorar las condiciones zoosanitarias de los animales.

Palabras clave: Papilomavirus bovino, Fibropapilomatosis bovina, Histopatología, PCR, San Luis Potosí.

Recibido: $21 / 08 / 2018$

Aceptado: 11/03/2020

La fibropapilomatosis bovina es una enfermedad viral infecciosa, especie específica y de distribución mundial que afecta principalmente bovinos jóvenes causada por el papilomavirus bovino (PVB) asociado a diversos factores predisponentes como estados de inmunosupresión, edad de los animales, estado nutricional, parasitosis, mal manejo, estrés, fármacos inmunosupresores entre otros ${ }^{(1,2)}$. Los papilomavirus son una familia de virus oncogénicos pequeños, no envueltos, capaces de infectar aves, mamíferos y peces. La familia papillomaviridae comprende 29 géneros que agrupan 189 tipos virales, de los cuales, 120 se han aislado de humanos, 64 de mamíferos, 3 de aves y 2 de reptiles ${ }^{(2,3)}$.

Hasta el momento, se han caracterizado 10 tipos virales capaces de causar infección en diferentes sitios anatómicos de los bovinos, y se ha descrito que dependiendo el tipo viral será la forma de presentación de la lesión. Así, el BPV-1 produce papilomas y fibropapilomas en la región del pene; el tipo 2, papilomas y fibropapilomas cutáneos y del tracto alimentario; los tipos 3 y 8, papilomas cutáneos; el tipo 4 se ha asociado a la aparición de papilomas del tracto gastrointestinal; el tipo 5, fibropapilomas en la ubre y los tipos 6, 9 y 10 se han encontrado asociados a la aparición de papilomas en ubres ${ }^{(3-7)}$.

Los fibromas, papilomas o fibropapilomas son neoplasias proliferativas benignas que pueden ser exofíticas o endofíticas, solitarias o múltiples, parcialmente delimitadas, tipo placa, papilares, con aspecto de grano de arroz o coliflor, secas y de consistencia firme que pueden necrosarse y desprenderse o exhibir contaminación bacteriana secundaria ${ }^{(8,9)}$.

Estas lesiones pueden tener regresión espontanea o permanecer hasta 6 a 18 meses; en caso de ser múltiples o dependiendo de su localización pueden ocasionar pérdida de la condición corporal. Los signos clínicos varían dependiendo de su localización; por ejemplo, si se localizan en espacio interdigital son dolorosos y pueden provocar cojeras o postración. En el tracto gastrointestinal, rara vez conducen a manifestaciones clínicas, pero pueden causar anorexia o timpanismo. En la glándula mamaria pueden dificultar el ordeño o complicarse 
con infecciones secundarias y generar mastitis. En vagina o pene pueden interferir con el coito, sangrar, infectarse e interferir con la reproducción ${ }^{(10-12)}$.

Histológicamente los papilomas están constituidos por proyecciones papilares de epitelio escamoso, sostenidas por estroma fibrovascular. El epitelio de estas proyecciones exhibe hiperplasia e hiperqueratosis, orto y paraqueratosis marcada. En algunos papilomas, los queratinocitos, principalmente los del estrato espinoso, presentan abundante citoplasma claro o un halo perinuclear y núcleos picnóticos, las cuales son denominadas coilocitos (células con cambios citopáticos). En ciertos papilomas en regresión se aprecia reducción de la hiperplasia epidermal, incremento en la proliferación de fibroblastos, depósitos de colágena e infiltración por linfocitos. Los fibropapilomas tienen dos componentes: el epitelio de revestimiento que alterna con tejido fibroso dispuesto en haces cortos entrelazados y fibroblastos reactivos. El epitelio de revestimiento no muestra cambios citopatológicos, pero presenta hiperplasia marcada y acantosis plexiforme ${ }^{(1,13,14)}$. En las lesiones grandes, el epitelio se puede erosionar semejando fibromas, en los cuales se observa proliferación de fibroblastos con depósitos de colágena densa ${ }^{(15)}$.

Se han desarrollado diferentes estrategias para la detección del PVB en fibromas y fibropapilomas mediante PCR. En este sentido, los oligonucleótidos FAP59/FAP64, diseñados a partir del análisis de regiones conservadas del gen L1 del papilomavirus humano (VPH), además de detectar un amplio espectro de tipos de VPH en tumores cutáneos y piel sana, han demostrado ser de utilidad en la detección de papilomavirus cutáneos de diversas especies, incluyendo los Papilomavirus bovinos tipo 1 - 12. De manera similar, los oligos MY09/MY11, diseñados originalmente para detectar tipos de VPH asociados a la mucosa y los genitales, han demostrado ser capaces de amplificar regiones del gen L1 de los tipos 1, 3, 56 del $\mathrm{PVB}^{(16,17)}$.

En México solamente se han informado datos de detección e identificación molecular de la infección por el PVB en el estado de Tamaulipas ${ }^{(18)}$. No existen datos epidemiológicos sobre la incidencia, prevalencia o los tipos virales más frecuentemente involucrados en el desarrollo de papilomas o fibropapilomas en ganado bovino de otras regiones del país. El objetivo de este trabajo es determinar la presencia de diferentes tipos de PVB en muestras de tejidos de bovinos con lesiones cutáneas con diagnóstico histopatológico de papilomas y fibropapilomas en diferentes regiones del estado de San Luis Potosí.

Se obtuvieron biopsias incisionales y excisionales de piel de bovino con lesiones sugerentes de fibromas, papilomas, y fibropapilomas de 11 animales de diferentes regiones del estado de San Luis Potosí (Cuadro 1 y Figura 1). 
Cuadro 1: Características de los bovinos incluidos en el muestreo

\begin{tabular}{llllll}
\hline ID & \multicolumn{1}{c}{ Raza } & Edad & Sexo & $\begin{array}{l}\text { Sistema de } \\
\text { producción }\end{array}$ & \multicolumn{1}{c}{ Ubicación } \\
\hline 1 & Suizo-Cebú & 18 meses & hembra & Estabulado & Tamuín \\
2 & Suizo-Cebú & 5 meses & macho & Agostadero & Éban \\
3 & Lidia & 6 meses & macho & Estabulado & Villa de Reyes \\
4 & Cruza de & 6 meses & macho & Semi- & Villa de Zaragoza \\
& Suizo & & & estabulado & \\
5 & Holstein & 15 meses & hembra & Estabulado & Soledad de Graciano Sánchez \\
6 & Holstein & 10 meses & hembra & Estabulado & Soledad de Graciano Sánchez \\
7 & Holstein & 10 meses & hembra & Estabulado & Soledad de Graciano Sánchez \\
8 & Holstein & 12 meses & hembra & Estabulado & Soledad de Graciano Sánchez \\
9 & Holstein & 13 meses & hembra & Estabulado & Soledad de Graciano Sánchez \\
10 & Cruza de & 7 meses & macho & Agostadero & Tamuín \\
& Cebú & & & & Tamasopo \\
11 & Cruza de & 8 meses & macho & Semi- & \\
& Suizo & & & estabulado & \\
\hline
\end{tabular}

Figura 1: Localización geográfica y cantidad de muestras obtenidas en las localidades del estado de San Luis Potosí

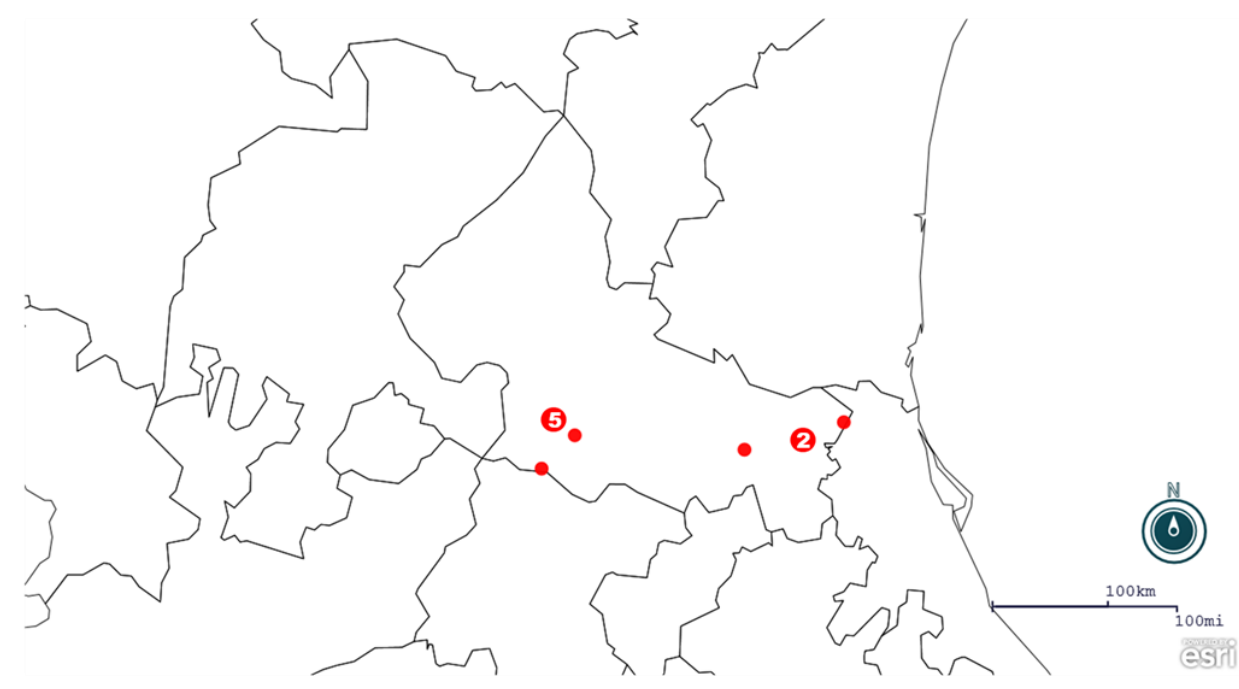

El tejido diseccionado se fragmentó en porciones pequeñas las cuales se dividieron para su estudio en dos partes: la primera porción se colocó en tubos Falcón de $15 \mathrm{ml}$ con formalina al 10\%, para su evaluación histopatológica y la segunda porción se colocó en una solución amortiguadora de fosfatos (PBS) pH 7.2 para la realización de PCR. Las muestras en PBS se colocaron en un contenedor criogénico y se transportaron al Laboratorio de Inmunología y 
Virología de la UASLP para su procesamiento. Las muestras colocadas en formaldehído fueron transportadas a temperatura ambiente al mismo laboratorio.

Para la evaluación histopatológica, los fragmentos de tejido previamente fijados en formalina al $10 \%$, se incluyeron en parafina y se procesaron por la técnica histológica de rutina, se hicieron cortes de 3 a $5 \mu \mathrm{m}$ de grosor y se tiñeron con hematoxilina y eosina (H\&E).

Para la extracción de ADN de las muestras colectadas se procesaron $25 \mathrm{mg}$ de tejido con el juego de reactivos DNeasy Blood \&Tissue (Qiagen, Valencia, California, EUA) siguiendo el procedimiento establecido por el fabricante. El ADN extraído fue almacenado a $-80^{\circ} \mathrm{C}$ hasta su uso. Para comprobar la pureza y cuantificar el ADN extraído, se empleó un microespectofotómetro de gota Nano-200 (All sheng, Beijing, China). Para verificar la integridad del ADN, se realizó una electroforesis en gel TAE-Agarosa al 2\%.

Las muestras de ADN fueron sometidas a PCR empleando las parejas de oligos FAP-59/FAP64 (Macrogen, Seoul Rep. de Korea) (FAP-59: 5'-TAACWGTIGGICAYCCWTATT-3'; FAP-64: 5'- CCWATATCWVHCATITCICCATC-3') y MY-09/MY-11 (IDT, San Diego, California, USA) (MY-09: 5'- CGTCCAAAAGGAAACTGAGC-3'; MY-11: 5'GCACAGGGACATAACAATGG-3'). Ambas parejas de oligos detectan el marco abierto de lectura del gen de la proteína mayoritaria de la cápside L1, altamente conservada en todos los tipos de PV bovinos y humanos.

Se prepararon mezclas de PCR de 50 $\mu$ l con el juego de reactivos para PCR Invitrogen (Invitrogen, Massachusetts, USA). Estas mezclas contenían: buffer 1×, DNTp $200 \mu \mathrm{M}$, $\mathrm{MgCl}_{2} 2 \mathrm{mM}$, oligonucleótidos $20 \mathrm{pM}$ y 5 UI de Taq polimerasa y $10 \mathrm{ng}$ de ADN. Estas mezclas se colocaron en un Termociclador Multigene Optimax (LabNET, California, USA). Para los oligos MY09/MY11, el programa de PCR consistió en 10 min de desnaturalización inicial a $94{ }^{\circ} \mathrm{C}, 35$ ciclos de 90 seg a $94{ }^{\circ} \mathrm{C}, 60$ seg a $50{ }^{\circ} \mathrm{C}, 90$ seg a $72{ }^{\circ} \mathrm{C}$ y una extensión final de 5 min a $72{ }^{\circ} \mathrm{C}$. Para la pareja FAP59/FAP64, el programa empleado consistió en 10 min de desnaturalización inicial a $94{ }^{\circ} \mathrm{C}, 45$ ciclos de $90 \mathrm{seg}$ a $94{ }^{\circ} \mathrm{C}, 90 \mathrm{seg}$ a $50{ }^{\circ} \mathrm{C}, 90 \mathrm{seg}$ a $72^{\circ} \mathrm{C}$ y una extensión final de $5 \mathrm{~min}$ a $72{ }^{\circ} \mathrm{C}$.

Los productos de PCR fueron analizados mediante electroforesis de $5 \mu \mathrm{l}$ del producto en gel de TAE-agarosa al 2\%. La electroforesis se realizó aplicando un voltaje de $80 \mathrm{~V}$ durante 80 min; transcurrido este tiempo, el gel se impregnó con bromuro de etidio (Sigma - Aldrich, Missouri, EUA) y la imagen se capturó con un fotodocumentador Gel Doc EZ System (BioRad, Hercules, California, EUA).

Las secciones histológicas de las 11 biopsias de piel, presentaban características en común tales como hiperplasia irregular e hiperqueratosis marcadas de la epidermis, erosiones, ulceras y costras serocelulares, en algunas, se observaron además proyecciones papilares 
sostenidas por estroma fibrovascular que alterna con colágena densa y degeneración epitelial balonoide con cuerpos de inclusión. En la dermis se observó proliferación de tejido conectivo fibroso maduro, entremezclado con fibroblastos reactivos, colágena densa, vasos linfáticos de nueva formación, así como múltiples agregados de linfocitos, células plasmáticas y macrófagos. Además, en una de las secciones de tejido se apreciaron células epiteliales atípicas dispersas, las cuales presentaban pérdida de la relación núcleo citoplasma, abundante citoplasma intensamente eosinofílico; núcleo grande, con escotaduras, cromatina desplazada a la periferia y uno a tres nucléolos evidentes (Figura 2).

Figura 2: Lesiones histológicas representativas de los fibromas, papilomas y fibropapilomas encontrados en la piel del ganado
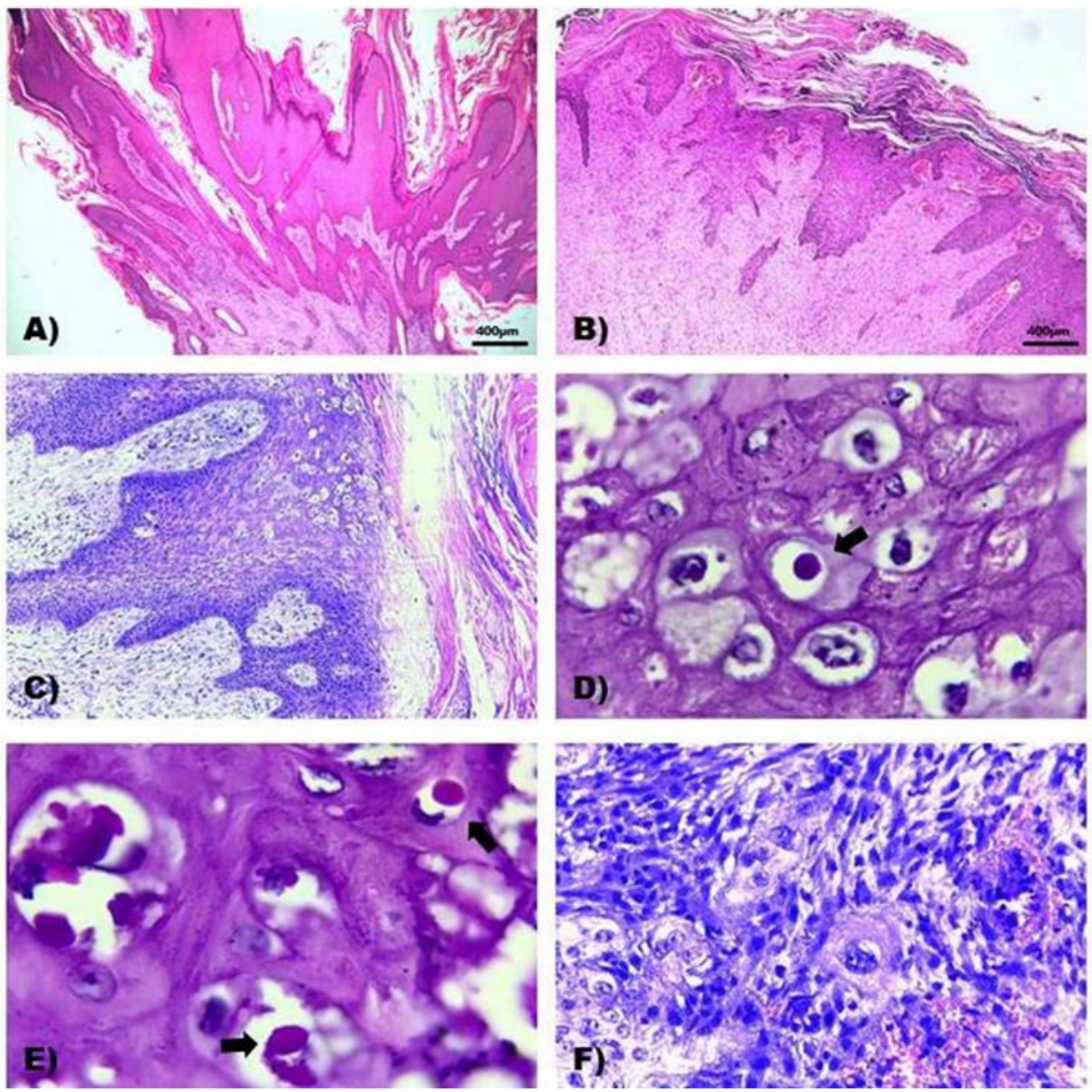

A) Fibropapiloma: la epidermis exhibe hiperplasia irregular e hiperqueratosis marcada difusa, así como formación de proyecciones papilares sostenidas por estroma fibrovascular. H\&E, 4X;

B) Fibroma: la epidermis exhibe hiperplasia irregular e hiperqueratosis marcada difusa, en la dermis se observa proliferación de tejido conectivo fibroso entremezclado con vasos sanguíneos congestionados y agregados de linfocitos y células plasmáticas. H\&E, 4X;

C) Fibroma: la epidermis exhibe hiperplasia irregular e hiperqueratosis marcada, además se observa degeneración balonoide de los queratinocitos en diferentes estratos; en la dermis se aprecia proliferación de fibroblastos reactivos y agregados de linfocitos y células plasmáticas. H\&E, 10X; D y E) Fibroma: los 
queratinocitos exhiben degeneración balonoide y presencia de estructuras anfofílicas amorfas compatibles con cuerpos de inclusión (Flecha) H\&E, 100X;

F) Fibroma: algunas células epiteliales exhiben marcada anisocariosis con pérdida de la relación núcleo citoplasma, abundante citoplasma intensamente eosinofílico; núcleo grande, con escotaduras, cromatina desplazada a la periferia y uno a tres nucléolos evidentes. H\&E, 40X.

Las lesiones histológicas observadas fueron sugerentes de un proceso neoplásico benigno de tipo viral compatibles con fibromas y fibropapilomas con base en características como: hiperplasia irregular e hiperqueratosis epidérmica, presencia de proyecciones papilares de la epidermis; proliferación de tejido conectivo fibroso maduro, entremezclado con fibroblastos reactivos, colágena densa y agregados de linfocitos, células plasmáticas y macrófagos. Además de presencia de coilocitos y cuerpos de inclusión anfofílicos intranucleares. Los diagnósticos histopatológicos definitivos se resumen en el Cuadro 2.

Cuadro 2: Finalidad de explotación de los bovinos, resultados histológicos y de PCR de las muestras obtenidas

\begin{tabular}{lllll}
\hline ID & Propósito de cría & Diagnóstico histológico & PCR FAP & PCR MY \\
\hline 1 & Carne & Fibroma & - & + \\
2 & Carne & Fibropapiloma & - & - \\
3 & Exhibición & Fibropapiloma & - & + \\
4 & Carne & Fibroma & + & + \\
5 & Leche & Fibropapiloma & + & + \\
6 & Leche & Fibropapiloma & + & + \\
7 & Leche & Fibroma & - & - \\
8 & Leche & Fibroma & - & - \\
9 & Leche & Fibropapiloma & - & - \\
10 & Carne & Fibroma & + & - \\
11 & Carne & Fibropapiloma & + & - \\
Total & & & 5 & 6 \\
\hline
\end{tabular}

En la reacción de amplificación con los oligos FAP59/FAP64, se observó un amplicón de entre 480 a $538 \mathrm{pb}$ correspondiente al producto de la amplificación por PCR del gen L1 de PVB en el $45.45 \%$ del total de las muestras $(n=5)$. En el $27.27 \%(n=3)$ del total de las muestras, no se observó ningún producto de PCR. De manera global, hasta un $72 \%$ de las muestras fueron positivas para secuencias de ADN correspondientes a secuencias del gen L1 del virus del PVB (Figura 3 y Cuadro 2). 
Figura 3: Producto de PCR con los oligos FAP59/FAP64

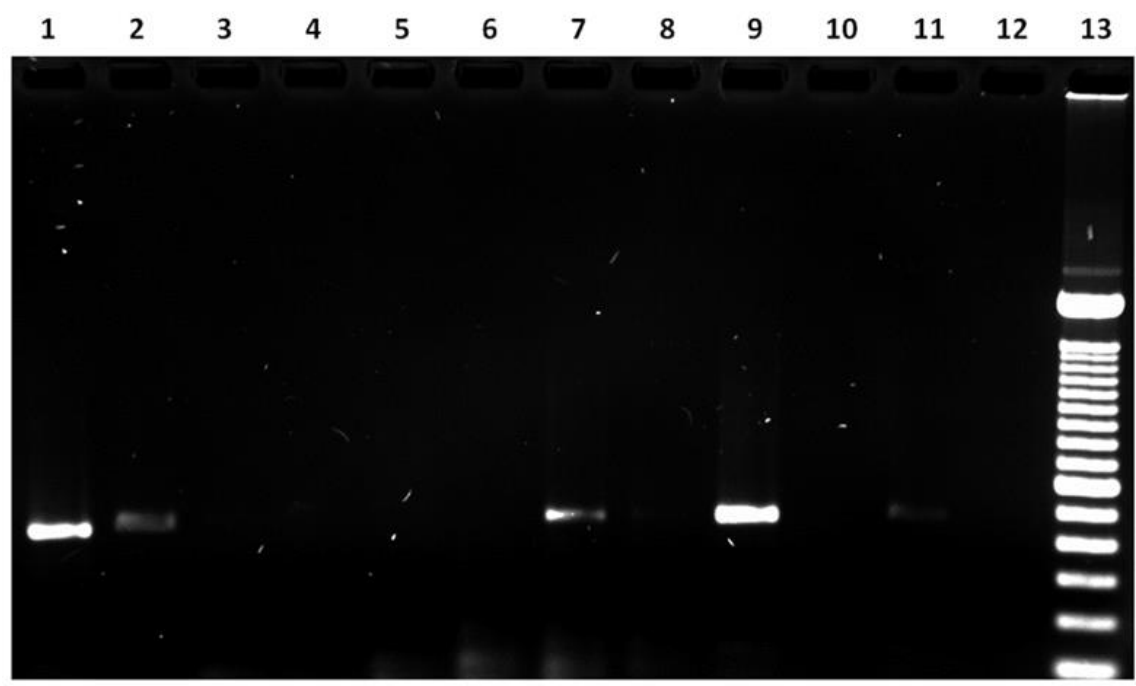

Carril 1: muestra 5, amplicón de 485 pb. Carril 2: muestra 6, amplicón de 511 pb; Carril 7: muestra 10, amplicón de 521 pb; Carril 9: muestra 11, amplicón de 515 pb; Carril 11: muestra 4, amplicón de 513 pb. Carril 12: testigo negativo (Sin DNA); Carril 13: escalera de 100 pb. Carriles 3, 4, 5, 6, 8 y 10: no se observa producto de PCR.

El análisis electroforético de los productos de PCR obtenidos con los oligos MY09/MY11 mostró bandas de entre 470 a 490 pb en las muestras 1, 2, 5, 6, 8 y 9 (54.5\% del total de las muestras), este amplicón es coincidente con el esperado para la PCR del gen L1 del virus del PVB (Figura 4).

Figura 4: PCR con los oligos MY09/11

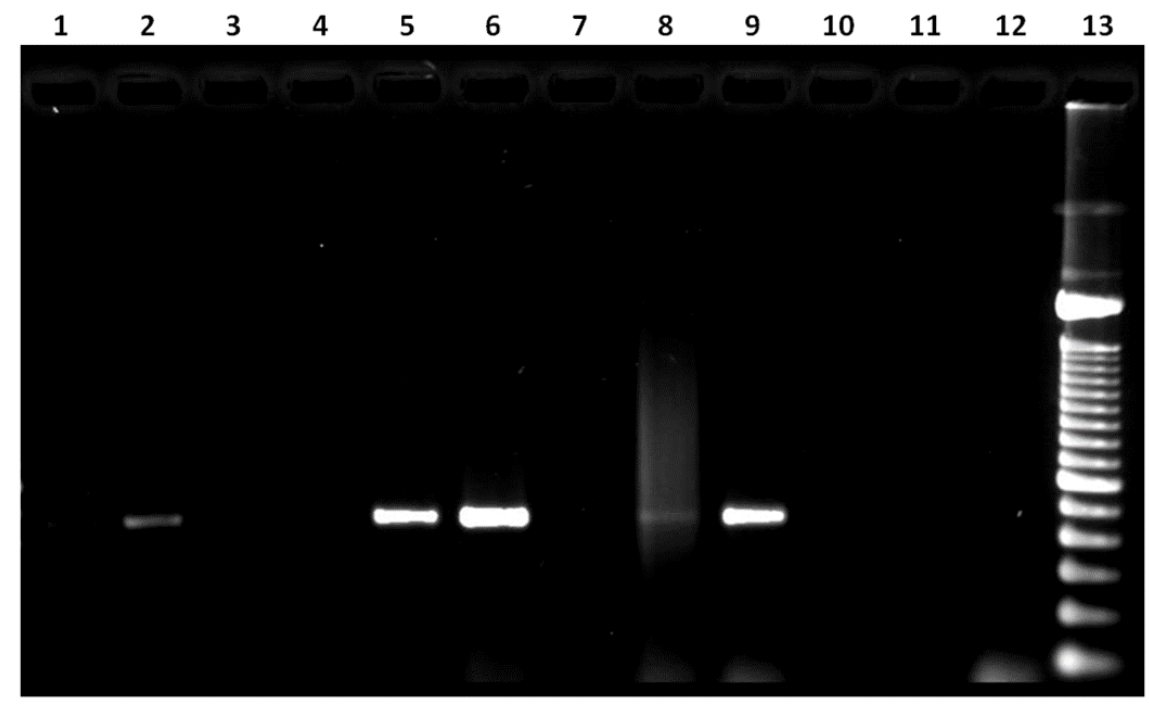

Carril 1: muestra 5, amplicón de 472 pb. Carril 2: muestra 6, amplicón de 479 pb; Carril 5: muestra 9, amplicón de 492 pb; Carril 6: muestra 1, amplicón de 488 pb; Carril 8: muestra 3, amplicón de 483 pb. Carril

9: muestra 4, amplicón de 486 pb Carril 12: testigo negativo (Sin DNA); Carril 13: escalera de 100 pb. Carriles 3, 4, 7, 10 y 11: no se observa producto de PCR. 
La mayoría de las lesiones examinadas fueron sugerentes de fibromas, sin embargo, es importante considerar que algunos papilomas y fibropapilomas pueden presentar regresión o cambios morfológicos durante su evolución que los hacen semejar fibromas en función de la cronicidad y estado inmunológico del animal ${ }^{(13,15)}$. Por esta razón es altamente probable que la incidencia de fibromas reportada en este trabajo esté sobreestimada con respecto al momento en que los animales fueron muestreados, dado que la etiología y evolución de estas lesiones pueden seguir un patrón común.

Las muestras incluidas en este estudio provenían de piel de diferentes regiones anatómicas de bovinos sin que se observara un patrón de restricción de las lesiones a una zona determinada en el cuerpo del animal. Estos resultados concuerdan con lo descrito por Borzacchiello et $a l^{(4)}$ quienes señalan que la presentación de lesiones cutáneas en la infección por PVB puede ser de manera generalizada y que además el sitio de aparición de estas lesiones se pueden correlacionar con el tipo viral involucrado.

Dado que las lesiones muestreadas se presentaron únicamente en la piel de los bovinos, es probable que los tipos virales involucrados correspondan al PVB-2, PVB-3, PVB-6 PVB-8 PVB-9 o PVB-10. Este hallazgo, sin embargo, deberá ser confirmado mediante secuenciación de los productos de PCR obtenidos.

Hasta donde se sabe, este es el primer trabajo que se ocupa de la detección a nivel molecular de la infección por el PVB en bovinos del estado de San Luis Potosí. Por lo cual los datos contenidos en este trabajo señalan las áreas de oportunidad en las cuales es necesario trabajar para implementar las medidas de detección y control necesarias para impactar favorablemente en la salud de los animales y mejorar la calidad de los productos pecuarios.

En la evaluación histológica, las lesiones más frecuentemente observadas en los fragmentos de piel, fueron la hiperplasia irregular de la epidermis, hiperqueratosis marcada difusa y degeneración balonoide de queratinocitos y en la dermis, proliferación de fibroblastos reactivos, tejido conectivo fibroso y agregados de linfocitos y células plasmáticas. Estas características han sido señaladas en extenso como lesiones sugerentes de una infección por papilomavirus $^{(19,20)}$.

Estudios previos realizados en Japón empleando la pareja de oligos FAP-59 / FAP-64 informan una prevalencia de hasta el $100 \%$ de PVB en lesiones cutáneas ${ }^{(21)}$. Un estudio en Irán informa una prevalencia del $12.5 \%$ en ganado Holstein ${ }^{(22)}$. En el presente estudio se encontró una frecuencia global de infección por algún tipo de PVB del $72 \%$; dato similar a lo informado por Santos et $\mathrm{l}^{(23)}$ quienes encontraron una prevalencia de hasta el $86 \%$ de muestras positivas a PVB en Brasil, y por Rojas et al ${ }^{(18)}$ quienes informan de 2 a $70 \%$ de muestras positivas en el estado de Tamaulipas, México. En el $27.27 \%$ de las muestras, las lesiones histológicas fueron altamente sugestivas de una infección viral, sin embargo, estas 
resultaron negativas por PCR a PVB por lo que no se descarta la posibilidad de asociación del PVB con estas lesiones, debido al proceso de integración genómica presente en la historia natural de la infección por $\mathrm{PVB}^{(4,24)}$.

Las infecciones por papilomavirus se han descrito en todo el mundo, aunque no todos los genotipos presentan la misma prevalencia regional ${ }^{(1,25,26)}$. En este trabajo se incluyeron muestras colectadas de bovinos de las regiones centro y huasteca del estado de San Luis Potosí, México, las cuales poseen climas muy diferentes entre sí (seco árido en el centro y subtropical en la huasteca). A pesar de que la mayoría de las muestras provenían de la región centro, los habitantes de las localidades de la región huasteca del estado informan de forma empírica una mayor incidencia de lesiones sugerentes de infección por PVB lo que concuerda con lo informado por Violet et $a l^{(27)}$ quienes señalan una probable asociación entre la frecuencia de presentación de papilomatosis cutánea y climas de tipo tropical lluvioso.

En este trabajo se describió por primera ocasión la presencia de PVB en bovinos del estado de San Luis Potosí, México. La presencia de este agente en bovinos de la entidad es alta, pero se considera similar a la encontrada en una región aledaña al estado y no se encuentra restringida a un patrón de presentación relacionado con la edad, raza o sistema de producción de los animales. Debido a que los tipos de PVB circulantes en el estado de SLP no han sido caracterizados hasta el tipo viral, es importante su identificación, lo que permitirá caracterizar patrones de distribución específicos (clúster) y el desarrollo de biológicos efectivos específicamente contra estos tipos virales.

\section{Agradecimientos}

La Maestra Isaura Méndez Rodríguez, desea agradecer al CONACYT (México) por la beca otorgada para realizar sus estudios doctorales.

\section{Conflictos de interés}

Los autores declaran no tener conflictos de interés, en relación a la elaboración, revisión y publicación de este trabajo.

\section{Literatura citada:}

1. Díaz RV, Duch CE, Gómez AD, Duato EGL, Rico LB. Papilomatosis bovina: epidemiología y diversidad de papilomavirus bovinos (BPV). Rev Complutense Cienc Vet 2012;6(2):38-58.

2. Fauquet CM, Mayo MA, Maniloff J, Desselberger U, Ball LA. Virus taxonomy: VIIIth report of the International Committee on Taxonomy of Viruses. California, USA: Academic Press; 2005. 
3. De Villiers EM, Fauquet C, Broker TR, Bernard HU, Zur Hausen H. Classification of papillomaviruses. Virology 2004;324(1):17-27.

4. Borzacchiello G, Roperto F. Bovine papillomaviruses, papillomas and cancer in cattle. Vet Res 2008;39(5):1.

5. Ogawa T, Tomita Y, Okada M, Shirasawa H. Complete genome and phylogenetic position of bovine papillomavirus type 7. J General Virol 2007;88(7):1934-1938.

6. Tomita Y, Literak I, Ogawa T, Jin Z, Shirasawa, H. Complete genomes and phylogenetic positions of bovine papillomavirus type 8 and a variant type from a European bison. Virus Genes 2007;35(2):243-249.

7. Hatama S, Nobumoto K, Kanno T. Genomic and phylogenetic analysis of two novel bovine papillomaviruses, BPV-9 and BPV-10. J General Virol 2008;89(1):158-163.

8. Pattar J. Autogenous vaccination and immunomodulation for management of cutaneous papillomatosis in a crossbred cow. Intas Polivet 2013;14(2):423-425.

9. Munday J. Bovine and human papillomaviruses: a comparative review. Vet Pathol 2014;51(6):1063-1075.

10. Corteggio A, Altamura G, Roperto F, Borzacchiello G. Bovine papillomavirus E5 and E7 oncoproteins in naturally occurring tumors: are two better than one? Infectious Agents and Cancer 2013;8(1):1.

11. Knight CG, Munday JS, Rosa BV, Kiupel M. Persistent, widespread papilloma formation on the penis of a horse: a novel presentation of equine papillomavirus type 2 infection. Vet Dermatol 2011;22(6):570-574.

12. Salib, FA, Farghali HA. Clinical, epidemiological and therapeutic studies on Bovine Papillomatosis in Northern Oases, Egypt in 2008. Vet World 2011;4(2)53-59.

13. Guzmán LSO, Barboza Q, González RRA. Biología del virus del papiloma humano y técnicas de diagnóstico. Medicina Universitaria 2010;12(49):231-238.

14. Henry M, Ioffe O. Squamous premalignancy of the cervix: advantages of a 2-tiered versus 3-tiered terminology. AJSP: Reviews \& Reports 2013;18(4):177-182.

15. Jang JS, Kim JH, Shin TK, Cho GJ, Kwon OD. A case of cutaneous fibroma in a Korean indigenous cattle. J Vet Clin 2008;25(3):200-201.

16. Forslund O, Antonsson A, Nordin P, Stenquist BO, Hansson BG. A broad range of human papillomavirus types detected with a general PCR method suitable for analysis of cutaneous tumours and normal skin. J General Virol 1999;80(9):2437-2443. 
17. Antonsson A, Hansson BG. Healthy skin of many animal species harbors papillomaviruses which are closely related to their human counterparts. J Virol 2002;76(24):12537-12542.

18. Rojas-Anaya E, Cantú-Covarrubias A, Álvarez JFM, Loza-Rubio E. Detection and phylogenetic analysis of bovine papillomavirus in cutaneous warts in cattle in Tamaulipas, Mexico. Canad J Vet Res 2016;80(4):262-268.

19. Jarrett WF, Campo MS, Blaxter ML, O'neil BW, Laird HM, Moar MH, et al. Alimentary fibropapilloma in cattle: a spontaneous tumor, nonpermissive for papillomavirus replication. J Natl Cancer Inst 1984;73(2):499-504.

20. Campo MS. Bovine papillomavirus and cancer. The Vet Journal 1997;154(3):175-188.

21. Ogawa T, Tomita Y, Okada M, Shinozaki K, Kubonoya H, Kaiho I, et al. Broad-spectrum detection of papillomaviruses in bovine teat papillomas and healthy teat skin. J General Virol 2004;85(8):2191-2197.

22. Babaahmady E, Taherpour K. Verrugas en los pezones de vacas lecheras. REDVET. Revista electrónica de Veterinaria 2011;12(6):1-6.

23. Santos EUD, Silva MAR, Pontes NE, Coutinho LCA, Paiva SSL, Castro RS, et al. Detection of different bovine papillomavirus types and co-infection in bloodstream of cattle. Transboundary Emerging Diseases 2016;63(1):e103-e10863.

24. Agrawal R, Pelkonen J, Rytkönen M, Mäntyjärvi RA. Integration of bovine papillomavirus type 1 DNA and analysis of the amplified virus-cell junctions in transformed primary mouse fibroblasts. J General Virol 1992;73(1):201-206.

25. Orozco ANM, Padilla MHJ. Manual alternativas de tratamiento contra la papilomatosis bovina [tesis doctoral]. Managua, Nicaragua: Universidad Nacional Agraria; 2016.

26. Charry DJV, Hinojosa LMB. Estudio de papilomatosis bovina en cinco propiedades de ganadería de leche, en cantón Pedro Vicente Maldonado en la provincia de Pichincha [tesis de licenciatura]. Quito, Ecuador: Universidad de las Américas; 2011.

27. Violet L, Montes D, Cardona J. Frecuencia de papilomatosis en bovinos (Bos taurus) del departamento de Córdoba, Colombia. Revista Colombiana de Ciencia Animal-RECIA 2017;9(2):294-300. 